\title{
$\mathrm{Sm}$ 농도변화에 따른 백색 LED용 ZnS:Mn,Sm형광체의 발광특성
}

\author{
이지영 ${ }^{1}$, 이상재 ${ }^{1}$, 김태우 ${ }^{1}$, 유 일 ${ }^{1, a}$ \\ 1 동의대학교 물리학과, 부산 IT융합부품연구소
}

\section{Luminescent Characteristics of ZnS:Mn,Sm Phosphors Prepared with Various Sm Concentration for White Light Emitting Diodes}

\author{
Ji-Young Lee ${ }^{1}$, Sang-Jae Lee ${ }^{1}$, Tae-Woo $\mathrm{Kim}^{1}$, and Il $\mathrm{Yu}^{1, \mathrm{a}}$ \\ ${ }^{1}$ Department of Physics, Dong-Eui University and Convergence of IT Devices Institute Busan, \\ Busan 614-714, Korea
}

(Received September 14, 2010; Revised November 8, 2010; Accepted November 17, 2010)

\begin{abstract}
ZnS:Mn yellow phosphors doped with Sm for white light emitting diodes were synthesized by solid state reaction method. These sample showed the characteristic X-ray diffraction patterns for main peak (110) of $\mathrm{ZnS}: \mathrm{Mn}, \mathrm{Sm}$. Photoluminescence excitation spectra originated from $\mathrm{Mn}^{2+}$ were ranged from $450 \mathrm{~nm}$ to $500 \mathrm{~nm}$. The yellow emission at around $580 \mathrm{~nm}$ was associated with ${ }^{4} \mathrm{~T}_{1} \rightarrow{ }^{6} \mathrm{~A}_{1}$ transition of $\mathrm{Mn}^{2+}$ ions in $\mathrm{ZnS}: \mathrm{Mn}, \mathrm{Sm}$ phosphors. The highest photoluminescence intensity of the phosphors under 405 $\mathrm{nm}$ and $450 \mathrm{~nm}$ excitation was obtained at Sm concentration of $1 \mathrm{~mol} \%$. The enhanced photoluminescent intensity in the $\mathrm{ZnS}: \mathrm{Mn}, \mathrm{Sm}$ phosphors was interpreted by energy transfer from Sm to Mn. The highest luminescent intensity of white LED was obtained at the epoxy-to-yellow phosphor ratio of 1:3. At this ratio, the CIE chromaticity of the white LED was $\mathrm{X}=0.3886$ and $\mathrm{Y}=0.2928$.
\end{abstract}

Keywords: ZnS, Luminescence, Mn, Sm, LED

\section{1. 서 론}

백색 light emitting diode (LED)는 에너지 소모량 이 적고, 수명이 반영구적인 환경 친화형 제품으로 백열등이나 형광등을 대체하는 가정용 조명과 liquid crystal display ( $\mathrm{LCD}$ )용 백라이트, 자동차 조명 등 산업용 조명에 제품이 확대 적용되고 있다 [1].

현재 백색 $\mathrm{LED}$ 를 얻는 방법은 각각의 $\mathrm{RGB} \mathrm{LED}$ 를 조합하거나, 청색계의 단일 칩상에 황색 형광체를 적용하는 방법, 그리고 자외선 발광 $\mathrm{LED}$ 칩에 $\mathrm{RGB}$ 형광체를 적용하는 방법이 있다. 현재, 고휘도 청색 $\mathrm{LED}$ 의 상용화에 따라 청색 $\mathrm{LED}$ 를 여기 광원으로 사

a. Corresponding author; 0324yu@deu.ac.kr
용하고 YAG:Ce 황색 형광체를 접목시킨 백색 $\mathrm{LED}$ 가 개발되었다. 그러나 $\mathrm{YAG:Ce을} \mathrm{제외한} \mathrm{일반적인}$ 형광체는 $380 \mathrm{~nm}$ 이상의 자외선 영역에서 낮은 휘도 를 나타낸다. 청색 $\mathrm{LED}$ 를 여기 광원으로 가시광 영 역에서 발광하는 황색 형광체는 청색 여기광과 에너 지 차이가 크기 않아 발광 효율이 낮기 때문에 형광 체 발광 효율을 더욱 개선할 필요가 있다. 이러한 문 제를 해결하기 위하여 발광중심으로 작용하는 활성 제, 형광체의 표면 처리 그리고 에너지 전이를 유도 하는 물질 첨가 등에 관한 연구가 진행되어 왔다.

$\mathrm{ZnS}$ 는 $3.7 \sim 3.8 \mathrm{eV}$ 의 높은 에너지 밴드 갭을 갖는 ПI-VI족 화합물 반도체로 $\mathrm{Cu}^{2+}, \mathrm{Mn}^{2+}$ 와 같은 전이금 속이나 $\mathrm{Eu}^{3+}$ 와 같은 희토류 금속을 첨가하면 청색, 녹 색, 황색, 적색 등 다양한 발광색을 유도할 수 있다 


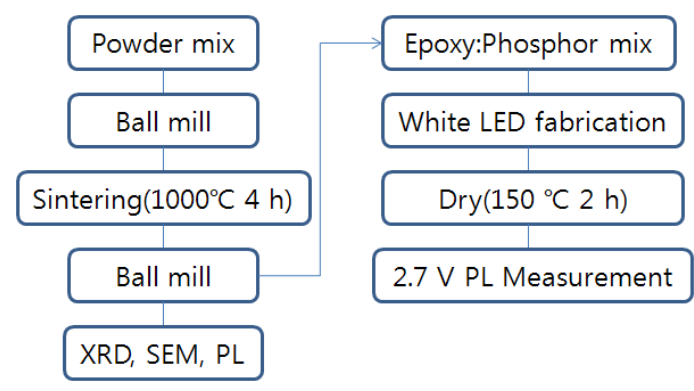

Fig. 1. Fabrication process for white LED.

[2].

기존의 $\mathrm{ZnS}$ 계 형광체는 과거로부터 많은 연구가 진행되어 왔지만 이러한 연구들은 여기파장을 380 $\mathrm{nm}$ 이하에서 진행 되었다. 고효율의 백색 LED용 형 광체를 개발하기 위해서는 백색 $\mathrm{LED}$ 용 광원인 405 $\mathrm{nm}$ 와 $450 \mathrm{~nm}$ 여기에 적합한 형광체 연구가 필요하 다.

따라서 본 연구에서는 에너지 전이를 유도하고, $405 \mathrm{~nm}$ 와 $450 \mathrm{~nm}$ 여기에 적합한 형광체를 얻기 위 해 기존의 가스 분위기와 달리 공기 중에서 일반적인 고상반응법으로 $\mathrm{Sm}$ 을 첨가한 $\mathrm{ZnS}: \mathrm{Mn}, \mathrm{Sm}$ 형광체를 제조하여 여기 조건에 따른 발광 특성을 연구하였다. 그 리고 백색 LED 특성은 $450 \mathrm{~nm} \mathrm{LED}$ 칩에 황색 형광 체를 도포하여 조사하였다.

\section{2. 실험 방법}

그림 1 은 고상반응법에 의한 $\mathrm{ZnS}: \mathrm{Mn}$ 형광체 제조 의 개략적인 공정도를 나타낸다. 그림 1 에서와 같이 $\mathrm{ZnS}: \mathrm{Mn}$ 형광체는 모체와 활성제로 $\mathrm{ZnS}$ (Aldrich, 99.9\%), $\mathrm{MnSO}_{4} \cdot 5 \mathrm{H}_{2} \mathrm{O}$ (Chemicals, 99.99\%), Sulfur (Kanto chemical, 99.9\%), $\mathrm{SmCl}_{2} \cdot 2 \mathrm{H}_{2} \mathrm{O}$ (Katayama, 99.9\%) 융제로 $\mathrm{NH}_{4} \mathrm{Cl}$ (Tedia, 99.99\%) 을 출발 원료 로 사용하였다. $\mathrm{Mn}$ 의 농도는 $0.5 \mathrm{~mol} \%$, 융제로 사용 되는 $\mathrm{NH}_{4} \mathrm{Cl}$ 의 농도는 $15 \mathrm{~mol} \%$ 로 고정 하고, $\mathrm{Sm}$ 의 농도는 0 2 $\mathrm{mol} \%$ 로 변화 시켰다. 볼밀 과정을 통해 균일하게 혼합된 분말은 $1000^{\circ} \mathrm{C}$ 에서 4 시간 동안 공 기 중에서 일반적인 고상반응법으로 합성 하였다. 합 성된 형광체의 결정구조는 $\mathrm{X}$ 선 회절기 (X-ray diffraction, XRD, RIGAKU 社)를 사용하여 확인하였다. Photoluminescence (PL)와 Photoluminescence excitation (PLE)은 Xe 램프의 $405 \mathrm{~nm}, 450 \mathrm{~nm}$ 를 여기광원으

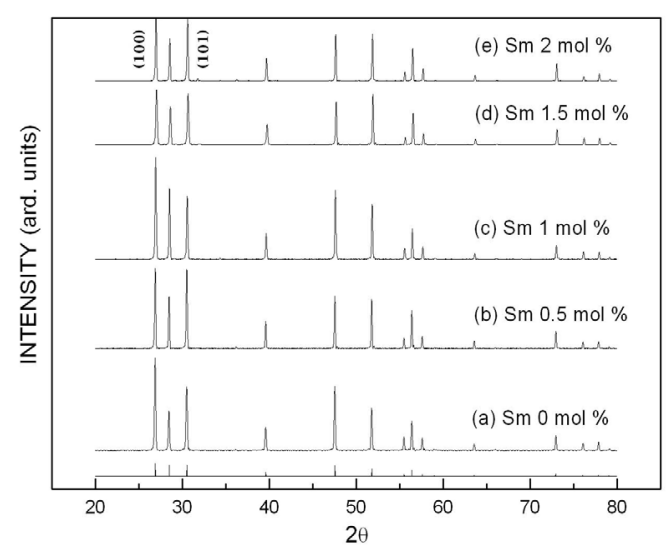

Fig. 2. XRD patterns of $\mathrm{ZnS}: \mathrm{Mn}, \mathrm{Sm}$ phosphors for various Sm concentration.

로 사용해 발광특성을 조사 하였다. 발광스펙트럼은 DARSA PRO-5000을 이용하여 $400 \mathrm{~nm} 700 \mathrm{~nm}$ 의 범위에서 분석하였다. 또한 백색 $\mathrm{LED}$ 는 에폭시와 황 색 형광체를 $1: 0$ 에서 1:4까지 무게 비율로 혼합한 페 이스트를 리드 프레임의 reflector cup에 주사기를 사 용하여 $450 \mathrm{~nm}$ 청색 LED 칩위에 볼록하게 도포하여 $150^{\circ} \mathrm{C}$ 에서 2 시간 건조하여 제조하였다. 예비실험으로 reflector cup위의 페이스트 도포 방법을 평편하게 도 포한 방법과 볼록하게 도포하여 제작하여 측정 하였 다. 몇 번의 예비 실험을 통해 볼록하게 도포한 방법 이 더 좋은 결과를 얻을 수 있어 본 실험에서는 볼록 하게 도포하여 측정 하였다. 또한, reflector cup위의 페이스트의 두께는 약 $0.3 \mu \mathrm{m}$ 였다.

백색 $\mathrm{LED}$ 측정은 $2.7 \mathrm{~V}$ 의 전압을 인가하여 발광 스 펙트럼을 분석하였다.

\section{3. 결과 및 고찰}

그림 2는 고상반응법으로 합성한 $\mathrm{ZnS}: \mathrm{Mn}$ 형광체에 서 $\mathrm{Sm}$ 농도변화에 따른 $\mathrm{XRD}$ 결과이다. JCPDS와의 비교에서 $\mathrm{ZnS}: \mathrm{Mn}, \mathrm{Sm}$ 은 $\mathrm{Sm}$ 농도 변화에 관계없이 (100), (101)면의 Hexagonal 구조가 잘 형성되어 있음 을 확인 하였다. 이 같은 결과로부터 발광 중심으로 작용하는 $\mathrm{Sm}$ 과 $\mathrm{Mn}$ 은 일정 농도 이상에서 다른 한쪽 이온의 끼어들기 자리에 위치하게 되어 $\mathrm{ZnS}$ 격자구 조의 찌그러짐을 초래 할 수 있으나, 그림에서와 같 이 그 영향은 미미한 것으로 생각된다. 또한, $\mathrm{Sm}$ 농 도 변화에 따른 피크의 반폭치는 $\mathrm{Sm} 1 \mathrm{~mol} \%$ 인 경우 


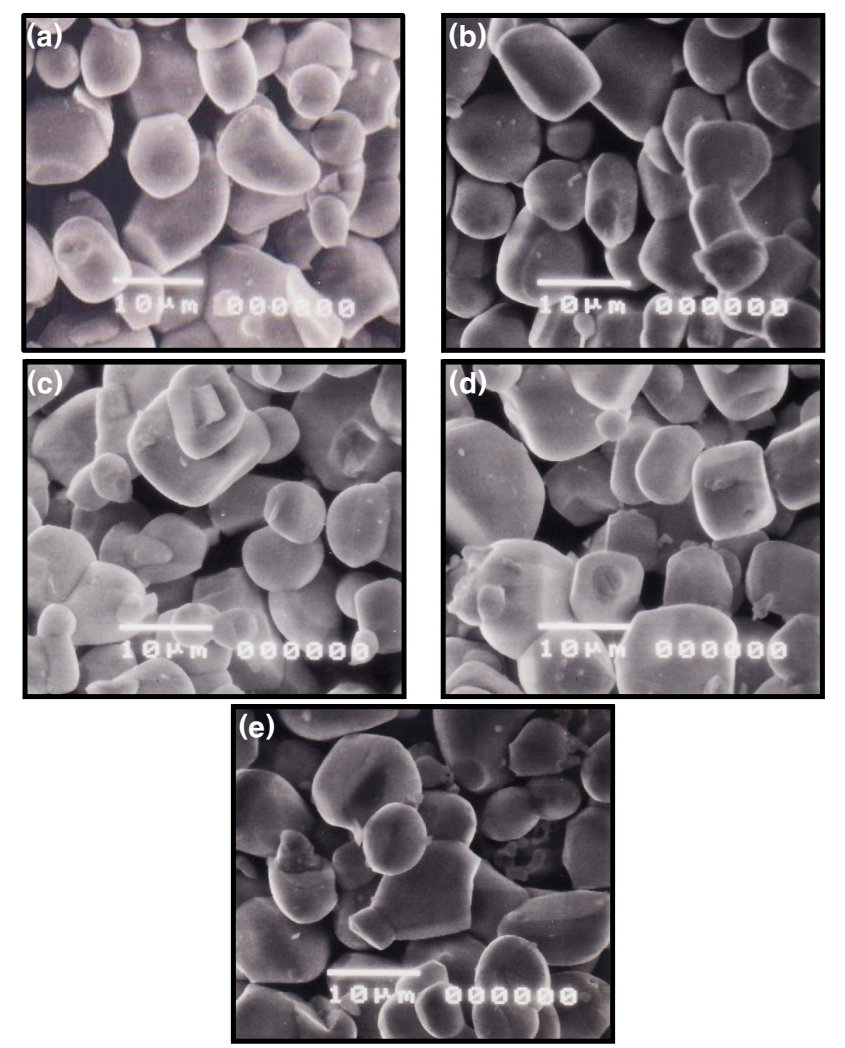

Fig. 3. SEM images of $\mathrm{ZnS}: \mathrm{Mn}, \mathrm{Sm}$ phosphors for various $\mathrm{Sm}$ concentration. (a) $\mathrm{Sm} 0 \mathrm{~mol} \%$, (b) $\mathrm{Sm} 0.5$ mol\%, (c) Sm $1 \mathrm{~mol} \%$, (d) Sm $1.5 \mathrm{~mol} \%$, (e) $\mathrm{Sm} 2$ $\mathrm{mol} \%$.

가장 작게 나타났고, 피크의 세기도 가장 우수하게 나타났다. 따라서 $\mathrm{Sm} 1 \mathrm{~mol} \%$ 첨가한 경우 결정성이 가장 양호하다고 생각된다.

그림 3 은 $\mathrm{Sm}$ 농도에 따른 $\mathrm{ZnS}: \mathrm{Mn}, \mathrm{Sm}$ 형광체의 $\mathrm{SEM}$ 사진이다. 그림에서와 같이 형광체는 표면이 매 우 매끄럽게 잘 생성되어 있었고, 입자 크기는 $8 \mu \mathrm{m}$ 에서 $12 \mu \mathrm{m}$ 로 나타났다.

그림 4는 $\mathrm{ZnS}: \mathrm{Mn}, \mathrm{Sm}$ 형광체에 $\mathrm{Sm}$ 의 농도 변화에 따른 PLE 스펙트럼의 변화를 나타내었다. PLE 스펙 트럼은 200 600 nm 구간에서 측정을 하였다. $\mathrm{ZnS}: \mathrm{Mn}, \mathrm{Sm}$ 형광체에서 $\mathrm{Sm}$ 농도가 증가함에 따라 $350 \mathrm{~nm}$ 부근의 모체 흡수와 관련된 피크의 세기는 증가 하였다. 또한 $\mathrm{Mn}^{2+}$ 에너지 준위와 관련된 400 $500 \mathrm{~nm}$ 부근의 피크들은 $\mathrm{Sm}$ 의 농도에 관계없이 모 두 비슷한 흡수 영역에서 관찰 되었고, 흡수 스펙트 럼의 세기는 $\mathrm{ZnS}: \mathrm{Mn}$ 형광체에 $\mathrm{Sm} 1 \mathrm{~mol} \%$ 첨가하 였을 때 가장 높게 나타났다

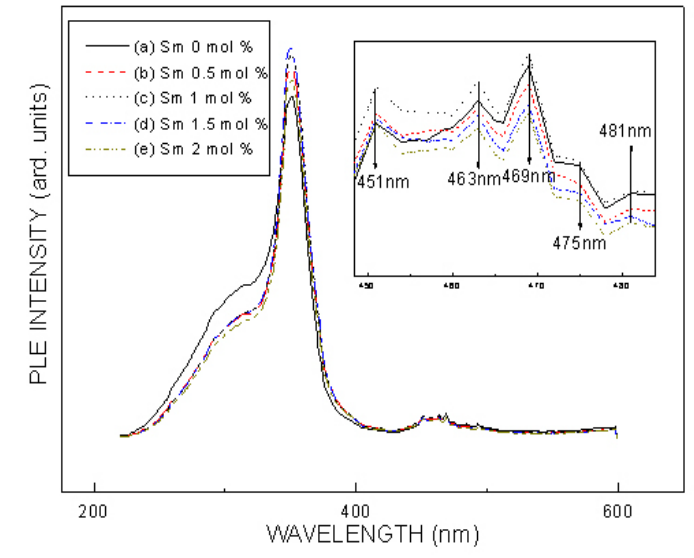

Fig. 4. PLE spectra of ZnS:Mn,Sm phosphors for various Sm concentration.

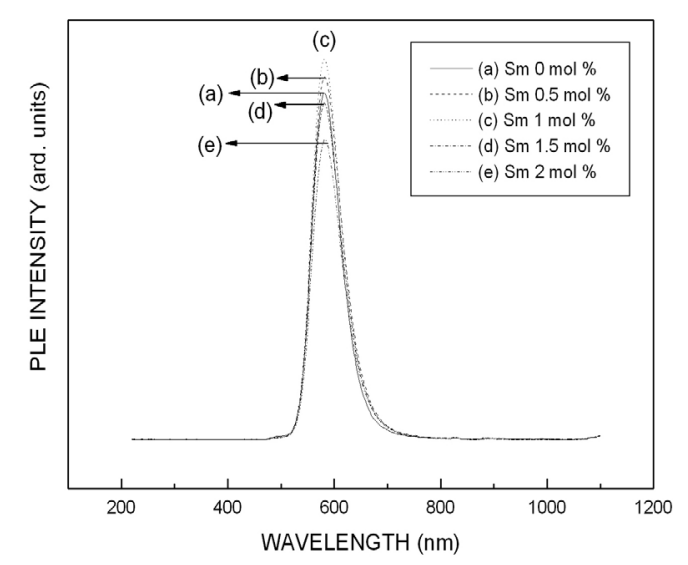

Fig. 5. PL spectra of $\mathrm{ZnS}: \mathrm{Mn}, \mathrm{Sm}$ phosphors for various Sm concentration under the $405 \mathrm{~nm}$ excitation.

그림 5 는 $405 \mathrm{~nm}$ 여기원에서 $\mathrm{Sm}$ 농도 변화에 따 른 $\mathrm{ZnS}: \mathrm{Mn}, \mathrm{Sm}$ 형광체의 $\mathrm{PL}$ 스펙트럼의 변화를 나 타내었다. $\mathrm{Sm}$ 를 첨가하지 않은 $\mathrm{ZnS}: \mathrm{Mn}$ 형광체의 $580 \mathrm{~nm}$ 에서 황색 발광 스펙트럼은 $\mathrm{Mn}^{2+}$ 이온의 $3 \mathrm{~d}^{5}$ 여기준위인 ${ }^{4} \mathrm{~T}_{1}\left({ }^{4} \mathrm{G}\right)$ 에서 $3 \mathrm{~d}^{5}$ 기저준위인 ${ }^{6} \mathrm{~A}_{1}\left({ }^{6} \mathrm{~S}\right)$ 의 전이 이다 [3]. 보고에 의하면 $\mathrm{ZnS}: \mathrm{Sm}$ 형광체의 발광 스펙트럼은 $\mathrm{Sm}^{3+}$ 이온의 ${ }^{4} \mathrm{G}_{5 / 2} \rightarrow{ }^{6} \mathrm{H}_{5 / 2}(565 \mathrm{~nm}),{ }^{4} \mathrm{G}_{5 / 2}$ $\rightarrow{ }^{6} \mathrm{H}_{7 / 2} \quad(600 \mathrm{~nm}),{ }^{4} \mathrm{G}_{5 / 2} \rightarrow{ }^{6} \mathrm{H}_{9 / 2}(650 \mathrm{~nm})$ 전이에 기인 하는 것으로 알려져 있다 [4 5]. 그림에서와 같이 발 광 세기는 $\mathrm{Sm}$ 의 농도가 $1 \mathrm{~mol} \%$ 에서 최대를 보였고, 그 이상 첨가한 경우 발광 휘도는 감소하였다. $\mathrm{Sm}$ 첨가에 따른 발광 세기의 증가는 $\mathrm{Sm}^{3+}$ 에서 $\mathrm{Mn}^{2+}$ 로의 


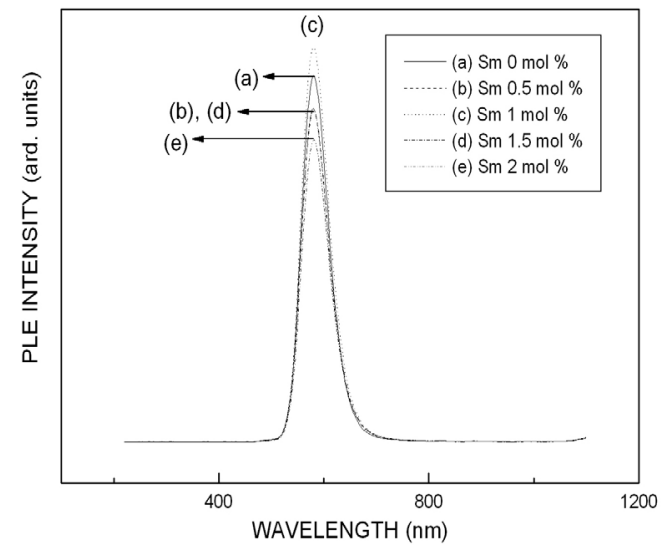

Fig. 6. PL spectra of $\mathrm{ZnS}: \mathrm{Mn}, \mathrm{Sm}$ phosphors for various Sm concentration under the $450 \mathrm{~nm}$ excitation.

에너지 전이에 의해 $580 \mathrm{~nm}$ 부근의 피크가 증가한 것으 로 생각된다. 또한, $\mathrm{Sm}$ 의 농도가 $1 \mathrm{~mol} \%$ 이상 첨가 한 형광체에서 발광 세기의 감소는 $\mathrm{ZnS}$ 결정내에 특 정 농도이상 $\mathrm{Sm}$ 이온이 첨가되면, $\mathrm{Sm}^{3+}$ 은 $\mathrm{Mn}^{2+}$ 로 에 너지 전이에 기여하지 못하고 전자산란 중심으로 작 용하기 때문에 발광의 세기가 감소되는 것으로 생각 된다.

그림 6 은 $450 \mathrm{~nm}$ 를 여기원으로 하여 측정한 $\mathrm{Sm}$ 농도 변화에 따른 $\mathrm{ZnS}: \mathrm{Mn}, \mathrm{Sm}$ 형광체의 $\mathrm{PL}$ 스펙트럼 의 변화를 나타내었다. 그림에서와 같이 $\mathrm{ZnS}: \mathrm{Mn}, \mathrm{Sm}$ 형광체는 $405 \mathrm{~nm}$ 를 여기원으로 측정한 $\mathrm{PL}$ 스펙트럼 과 비슷하게 $\mathrm{Sm}$ 농도에 관계없이 $580 \mathrm{~nm}$ 에서 발광 피크가 나타났다. 또한, $\mathrm{Sm}$ 의 농도가 $1 \mathrm{~mol} \%$ 첨가한 경우 발광 세기가 가장 높게 나타났다. 이것은 앞서 설명한 것과 마찬가지로 $\mathrm{Sm}$ 을 첨가함에 따라 $\mathrm{Sm}^{3+}$ 에 서 $\mathrm{Mn}^{2+}$ 로의 에너지 전이에 의해 $580 \mathrm{~nm}$ 부근의 피크가 증가한 것으로 생각된다.

그림 7과 8은 $405 \mathrm{~nm}$ 와 $450 \mathrm{~nm}$ 여기원으로 하여 측정한 $\mathrm{Sm}$ 농도변화에 따른 $\mathrm{ZnS}: \mathrm{Mn}, \mathrm{Sm}$ 형광체의 $\mathrm{CIE}$ 색좌표 변화를 나타내었다. $\mathrm{Sm}$ 을 $1 \mathrm{~mol} \%$ 첨가 한 형광체에서 $405 \mathrm{~nm}$ 와 $450 \mathrm{~nm}$ 여기원으로 각각 측정한 색좌표는, $\mathrm{X}=0.5293, \mathrm{Y}=0.4680$ 와 $\mathrm{X}=0.5199$, $\mathrm{Y}=0.4774$ 로 나타났다.

그림 9는 앞의 결과에서 가장 우수한 발광 세기를 보인 $\mathrm{Sm} 1 \mathrm{~mol} \%$ 첨가한 $\mathrm{ZnS}: \mathrm{Mn}$ 형광체를 에폭시 와 무게 비율로 혼합하여 제작한 백색 $\mathrm{LED}$ 의 발광 스펙트럼이다. 그림에서와 같이 형광체의 비율이 높 아짐에 따라 $450 \mathrm{~nm} \mathrm{LED}$ 자체 스펙트럼의 피크 세

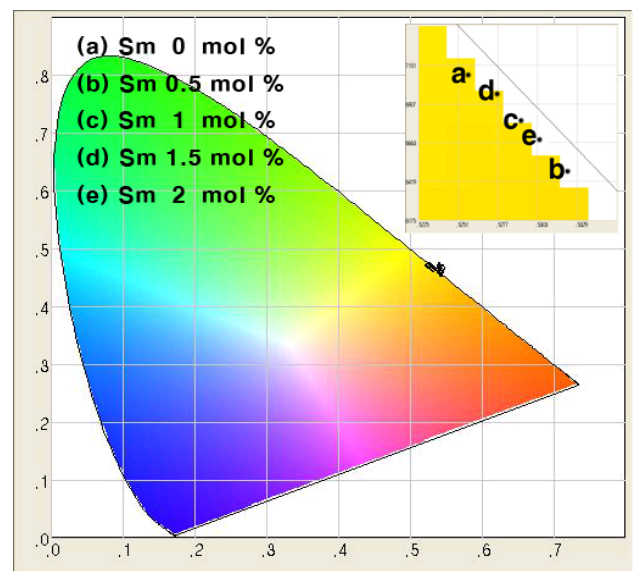

Fig. 7. CIE diagram of $\mathrm{ZnS}: \mathrm{Mn}, \mathrm{Sm}$ phosphors under the $405 \mathrm{~nm}$ excitation.

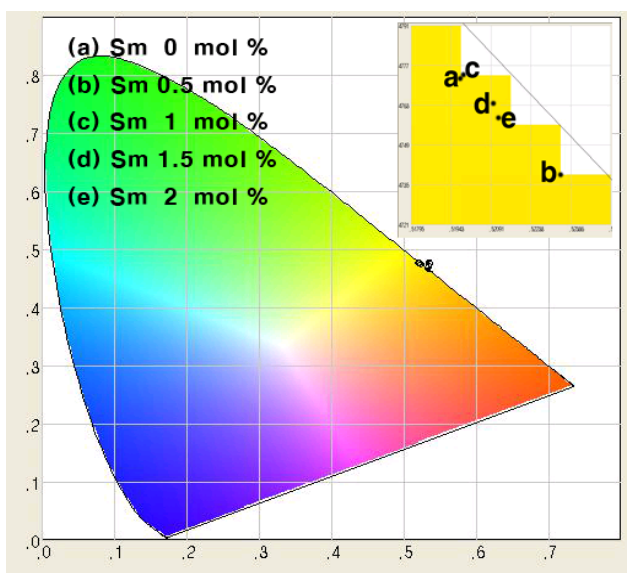

Fig. 8. CIE diagram of $\mathrm{ZnS}: \mathrm{Mn}, \mathrm{Sm}$ phosphors under the $450 \mathrm{~nm}$ excitation.

기는 줄어들고, 형광체의 중심 파장인 $580 \mathrm{~nm}$ 피크가 증가하였다.

그림 10 은 형광체와 에폭시와의 무게 비율에 따른 색좌표 변화를 나타내었다. 형광체를 도포하지 않은 $450 \mathrm{~nm} \mathrm{LED}$ 칩은 청색으로 나타났지만, 에폭시와 형광체의 비율이 $1: 3$ 인 $\mathrm{LED}$ 는 거의 백색에 가까운 색좌표가 나타났다. 하지만 에폭시와 형광체의 비율 이 $1: 3$ 이상의 경우에서는 형광체의 발광 중심인 580 $\mathrm{nm}$ 부근의 피크가 증가하여 백색이 아닌 황색으로 색좌표가 변화하였다. $450 \mathrm{~nm} \mathrm{LED} \mathrm{칩에} \mathrm{황색} \mathrm{형광}$ 체를 도포하여 제작한 백색 $\mathrm{LED}$ 의 최적 조건은 에폭 시와 형광체의 비율이 $1: 3$ 이고, 이 때 색좌표는 


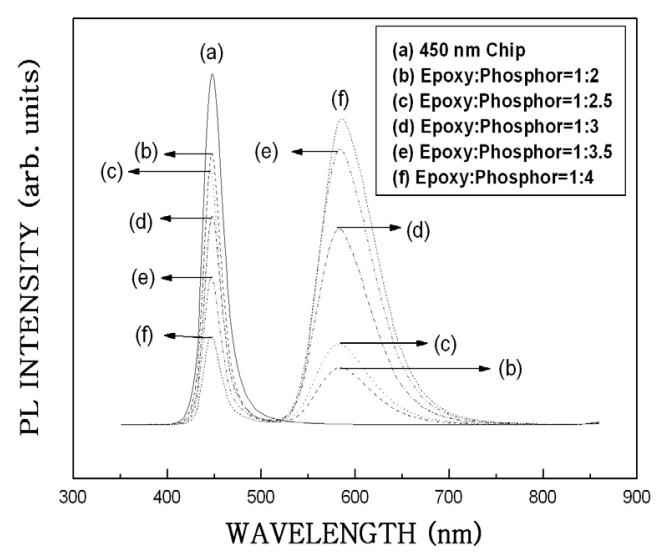

Fig. 9. PL spectra of $\mathrm{ZnS}: \mathrm{Mn}$ phosphors for various Sm concentration under the $450 \mathrm{~nm}$ excitation wavelength.

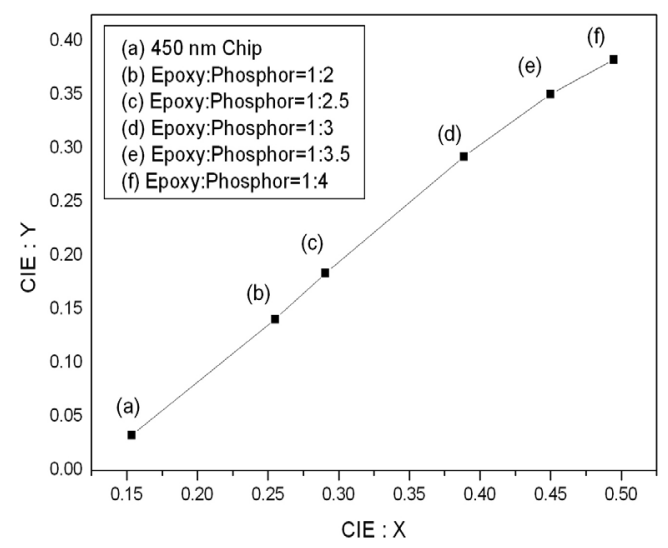

Fig. 10. CIE chromaticity points of blue LED-based ZnS:Mn,Sm LED.

$\mathrm{X}=0.3886, \mathrm{Y}=0.2928$ 그리고 색온도 $(\mathrm{CCT})$ 는 $2800 \mathrm{~K}$ 였다.

\section{4. 결 론}

$\mathrm{ZnS}: \mathrm{Mn}, \mathrm{Sm}$ 형광체를 $\mathrm{Sm}$ 농도 변화에 따라 고상
반응법으로 제조하여 발광특성을 분석하였다. XRD 결과 $\mathrm{ZnS}: \mathrm{Mn}, \mathrm{Sm}$ 형광체는 $\mathrm{Sm}$ 농도에 관계없이 (100), (101)면의 hexagonal 구조가 잘 형성되어 있음 을 확인 할 수 있었다. $405 \mathrm{~nm}$ 와 $450 \mathrm{~nm}$ 여기원으로 측정한 $\mathrm{ZnS}: \mathrm{Mn}, \mathrm{Sm}$ 형광체의 $\mathrm{PL}$ 결과는 $\mathrm{Sm}$ 의 농도 가 $1 \mathrm{~mol} \%$ 일 때, 최적의 발광조건을 보였다. $\mathrm{Sm}$ 을 첨가함에 따라 $580 \mathrm{~nm}$ 부근의 피크가 증가한 것은 $\mathrm{Sm}^{3+}$ 에서 $\mathrm{Mn}^{2+}$ 로의 에너지 전이에 의한 것으로 생각된다. 또 한 $\mathrm{Sm}$ 농도 변화에 따른 $\mathrm{CIE}$ 색좌표 변화를 관찰한 결과, $\mathrm{Sm}$ 를 $1 \mathrm{~mol} \%$ 첨가한 $\mathrm{ZnS}: \mathrm{Mn}$ 형광체에서 405 $\mathrm{nm}$ 와 $450 \mathrm{~nm}$ 여기원으로 각각 측정한 색좌표는, $\mathrm{X}=0.5293, \mathrm{Y}=0.4680$ 와 $\mathrm{X}=0.5199, \mathrm{Y}=0.4774$ 로 각각 나 타났다. $1 \mathrm{~mol} \% \mathrm{Sm}$ 을 첨가한 $\mathrm{ZnS}: \mathrm{Mn}$ 형광체를 에 폭시와 무게 비율로 혼합하여 제작한 백색 $\mathrm{LED}$ 의 발 광 스펙트럼을 조사한 결과, 에폭시와 형광체의 비율 이 $1: 3$ 일 때 백색 $\mathrm{LED}$ 에 가장 가까웠고, 이 때 색좌 표는 $\mathrm{X}=0.3886, \mathrm{Y}=0.2928$ 그리고 색온도 (CCT)는 $2800 \mathrm{~K}$ 였다.

\section{감사의 글}

이 논문은 2010학년도 교육과학기술부 및 한국과학 창의재단이 지원한 연구 결과임.

\section{REFERENCES}

[1] H. J. Chang, C. S. Son, and J. S. Hur, J. Kor, Inst, Surf, Eng, 40, 103 (2007).

[2] S. D. Han, A. K. Kwon, H. S. Lee, C. H. Han, J. D. Kim, and J,-H, Gwak, J. Korean Sensors Soc. 15, 323 (2006).

[3] J. S. Kim, T. W. Kim, H. L. Park, and S. D. Han, J. Kor. Soc. Imag. Sci. Technol. 10, 8 (2004).

[4] K. H. Choi, Y. M. Im, C. J. Lee and B. H. Jung, J. Opt. Soc. Kor. 3, 111 (1992).

[5] T. P. Tang, M. R. Yang, and K. S. Chen, Ceramics International 26, 341 (2000). 